Tohoku J. Exp. Med., 1995, 177, 93-106

\title{
Significance of the Right Ventricular Free Wall in Dogs with and without Pulmonary Constriction
}

\author{
Kei Munakata, Kunio Shirato, Ken Ishikawa, \\ Masahito Sakuma, Masaharu Kanazawa, Takashi \\ Haneda and Tamotsu Takishima
}

The First Department of Internal Medicine, Tohoku University School of Medicine, Sendai 980-77

Munakata, K., Shirato, K., Ishikawa, K., Sakuma, M., Kanazawa, M., Haneda, T. and Takishima, T. Significance of the Right Ventricular Free Wall in Dogs with and without Pulmonary Constriction. Tohoku J. Exp. Med., 1995, 177 (2), 93-106 — To evaluate the role of the right ventricular (RV) free wall in cardiac function, $\mathrm{RV}$ and left ventricular $(\mathrm{LV})$ wall segment lengths were measured by ultrasonic crystals in 10 open chest dogs with the pericardium preserved. Right coronary artery (RCA) was perfused separately by own blood and the flow was reduced stepwise until active shortening $(\Delta \mathrm{L})$ of the $\mathrm{RV}$ segment disappeared or RCA flow became zero (Ischemia). The experiment was repeated with and without pulmonary stenosis (PS). At Ischemia, RV and LV systolic pressures decreased. RV end-diastolic length increased and $\mathrm{RV} \triangle \mathrm{L}$ decreased. $\mathrm{LV}$ enddiastolic length and $\mathrm{LV} \Delta \mathrm{L}$ were reduced. $\mathrm{LV}$ stroke volume concurrently fell. These changes became more prominant with PS. The critical level of RCA flow, at which RV $\Delta \mathrm{L}$ began to change, was higher with PS $(5.27 \pm 2.85 \mathrm{ml} / \mathrm{min}$, mean \pm S.D.) than without PS $(1.44 \pm 1.16, p<0.01)$. Based on the relationships between $\mathrm{RV} \triangle \mathrm{L}$ and percent changes in $\mathrm{RV}$ developed pressure and stroke volume, the degree of the decreases in $\mathrm{RV}$ developed pressure and stroke volume at $\mathrm{RV} \Delta \mathrm{L}$ of zero were estimated to be about $20 \%$. These results indicate that the RV free wall partly contributes to maintaining the RV function, especially during RV pressure overload. critical coronary flow; pressure load; right ventricular function; stroke volume

The significance of the right ventricular free wall in cardiac function has long been questioned. Following a report by Starr et al. (1943), the right ventricular free wall has been thought not to participate in maintaining cardiac function. In contrast, right ventricular infarction sometimes shows a severely depressed state of cardiac function in the clinical settings (Cohn et al. 1974; Coma-Canella et al. 1979; Lorell et al. 1979; Coma-Canella and Lopez-Sendon 1980; Lloyd et al. 1981; Lopez-Sendon et al. 1981). In addition, the right ventricular stroke volume is

Received October 12, 1994; revision accepted for publication August 5, 1995.

Address for reprints: Kunio Shirato, M.D., The First Department of Internal Medicine, Tohoku University School of Medicine, 1-1 Seiryomachi, Aoba-ku, Sendai 980-77, Japan. 
known to be mainly maintained by bellows action, which consists of the cooperative movements of both the right ventricular free wall and the interventricular septum (Rushmer et al. 1953). Thus, it appears that the right ventricular free wall partly contributes to maintaining right ventricular function.

Therefore, the present study was designed to clarify the significance of the right ventricular free wall in cardiac function. We induced a depression of right ventricular free wall function through the stepwise reduction in right coronary artery flow, and examined the changes in cardiac function, especially changes in the right ventricular developed pressure and left ventricular stroke volume in relation to the right ventricular free wall movement, under conditions with and without pulmonary stenosis.

\section{Materials and Methods}

\section{Surgical preparations}

Ten mongrel dogs weighing from 13.6 to $23.5 \mathrm{~kg}$ (mean $17.9 \mathrm{~kg}$ ) were anesthetized with intravenous pentobarbital sodium $(30 \mathrm{mg} / \mathrm{kg})$. After endotracheal intubation, respiration was maintained mechanically with a constant volume respirator (tidal volume; $15 \mathrm{ml} / \mathrm{kg}$, respiration rate; $12-15$ cycles $/ \mathrm{min}$, positive end-expiratory pressure of $5 \mathrm{cmH}_{2} \mathrm{O}$ ) with room air and supplemental oxygen. Arterial blood was repeatedly sampled and its $\mathrm{PaO}_{2}$ and $\mathrm{pH}$ were maintained within their physiologic ranges. Bilateral thoracotomy was performed in the fourth or fifth intercostal space. Ultrasonic dimension system (Model 401; Schuessler, San Diego, CA, USA) was employed for measuring segment length of right and left ventricular myocardia as previous reports (Shirato et al. 1978, 1982; Pouleur et al. 1980; Kanazawa et al. 1983). Briefly, two pairs of small incisions approximately $10 \mathrm{~mm}$ apart were made in the pericardium, and two pairs of ultrasonic crystals $(5 \mathrm{MHz}, 2 \mathrm{~mm}$ in diameter) were implanted into the anterior free walls of the right and left ventricles in the direction of the minor equator of the left ventricle. Another small incision was made in the pericardium, and the right coronary artery was dissected free near its origin. The right coronary artery was then cannulated and perfused by blood from the femoral artery, and the flow rate was measured with an electromagnetic flowmeter (MF-46; Nihon Kohden Instrument, Tokyo) and adjusted with a roller pump. Heparin was administered intravenously as an initial bolus injection of 5,000 U, and 2,000 $\mathrm{U}$ were infused every 30 min thereafter.

In addition, another electromagnetic flow probe was placed around the aortic root for measuring left ventricular stroke volume and a snare around the pulmonary trunk for later constriction through incisions in the pericardium. All the incisions were loosely sutured with care taken not to reduce the original space of the pericardial sac.

Two catheters were inserted into the right and left ventricles for measuring each ventricular pressure (23Db; Statham Instruments, Oxnard, CA, USA) 
through the right jugular vein and right carotid artery, respectively. In all the dogs except one, right ventricular pressure was also measured using a catheter-tip micromanometer with a fluid-filled lumen (PC-480; Millar Instrument, Houston, TX, USA). In two dogs whose heart rates decreased by more than 10 beats $/ \mathrm{min}$ during stepwise reduction of the right coronary flow, electrodes were sutured onto the left atrium, and pacing at the individual animals own rate in the control stage was performed with a demand type pacemaker (5880 A; Medtronic Inc., Minneapolis, MN, USA). Respiratory cycle was monitored with a thermister placed inside the endotracheal tube.

\section{Experimental protocol}

Right coronary artery flow was maintained at the level of $30 \mathrm{ml} / \mathrm{min}$ and a stable state was confirmed for at least 10 min (control stage). The flow was then reduced stepwise every 3 min until either right coronary artery flow reached zero or an active shortening (end-diastolic length-end-systolic length) of the right ventricular segment almost disappeared, and then the right coronary artery flow was promptly returned to the control level $(30 \mathrm{ml} / \mathrm{min})$. The experiment was repeated when right ventricular systolic pressure was elevated by about $20 \mathrm{mmHg}$ by means of pulmonary stenosis using an instrumented snare around the pulmonary trunk. In two of 10 dogs, the same protocol was repeated twice and we confirmed the reproductivity.

After each experiment was finished, the crystals implanted into the myocardium were inspected and the suitability of the placement was confirmed. Weights of total heart, left ventricle including interventricular septum, and right ventricular free wall were measured.

\section{Data analysis}

All the data including electrocardiogram, respiratory cycle, right and left ventricular pressures, right and left ventricular segment lengths, aortic and right coronary artery flows were monitored on a multi-channel recorder and stored on a data recorder (FE $3907 \mathrm{~W}$; Sony Magnescale Inc., Tokyo) for subsequent replay on an ink-less recorder (8K 10; San-ei Instrument, Tokyo) at a paper speed of 100 $\mathrm{mm} / \mathrm{sec}$. The end-diastolic point was determined at onset of the ventricular contraction using the expanded pressure tracing. The end-systolic point was determined as the minimum of the ventricular length just before the peak negative first derivative of left ventricular pressure $(\mathrm{dP} / \mathrm{dt})$ in the control stage. In successive stages, corresponding points were determined as end-diastolic and end-systolic points by visual inspection (Fig. 1). Right and left ventricular end-diastolic and end-systolic segment lengths were determined at end-diastolic and end-systolic points, respectively. Active shortening of each ventricular segment length was calculated by subtracting end-systolic length from enddiastolic length. For comparison of the segment lengths, each measured value 
was normalized to the end-diastolic length in steady state just before right coronary artery cannulation, which was taken to be $10 \mathrm{~mm}$. All the data were obtained in the end-expiratory phase.

All dogs exhibited an obvious value of right coronary artery flow, termed the "critical flow", at which the right ventricular end-systolic segment length began to increase by $3-6 \%$ at $3 \mathrm{~min}$ after the right coronary artery flow was adjusted to the critical flow. Data were gathered and analyzed at the following four points: the control stage, the critical point which was defined as the time at the critical flow, ischemia when the right coronary artery flow was minimum, and the recovery stage which was defined as the time at $3 \mathrm{~min}$ after the right coronary artery had returned to the control level.

\section{Statistics}

All data except Fig. 3 were expressed as mean \pm standard deviation (s.D.) and the differences in means were assessed by one-way repeated-measures analysis of variance (ANOVA). Also, simultaneous multiple comparisons between groups were made by Bonferroni's method. A $p$-value less than 0.05 was regarded as statistically significant.

\section{RESULTS}

Representative tracings of both ventricular pressures, segment lengths, and aortic flow obtained from one dog are shown in Figs. 1 and 2. At the critical point, right ventricular segment length, especially end-systolic length, began to increase. At ischemia, the right ventricular end-diastolic and end-systolic lengths further increased, and its active shortening reduced markedly. Aortic flow and right and left ventricular systolic pressures decreased. At recovery, these changes returned to the control levels.

Mean values of general hemodynamics and segment lengths of both ventricles from ten dogs are shown in Table 1. With pulmonary stenosis, right ventricular systolic and developed pressures at control increased by $20.8 \pm 7.5$ and $19.4 \pm 7.6$ $\mathrm{mmHg}$, respectively, compared to values without pulmonary stenosis (both, $p<$ 0.001 ), and right coronary artery flow at the critical point was significantly higher than that without pulmonary stenosis $(5.27 \pm 2.85$ vs. $1.44 \pm 1.16 \mathrm{ml} / \mathrm{min}, p<0.01)$.

Responses of right and left ventricular segment lengths to right coronary artery flow reduction are summarized in Table 2. At ischemia without pulmonary stenosis, right ventricular end-diastolic and end-systolic lengths increased from $9.83 \pm 0.34$ to $10.33 \pm 0.39 \mathrm{~mm}$ and from $8.17 \pm 0.33$ to $9.33 \pm 0.82 \mathrm{~mm}$ (both, $p<0.001)$, respectively, and active shortening clearly decreased from $1.66 \pm 0.42$ to $1.00 \pm 0.76 \mathrm{~mm}(p<0.001)$. In contrast, left ventricular end-diastolic length decreased from $9.85 \pm 0.23$ to $9.57 \pm 0.28 \mathrm{~mm}(p<0.05)$, while end-systolic length remained unchanged, and an active shortening of the left ventricular segment was reduced from $1.83 \pm 0.64$ to $1.68 \pm 0.56 \mathrm{~mm}(p<0.05)$. At recovery, these changes 


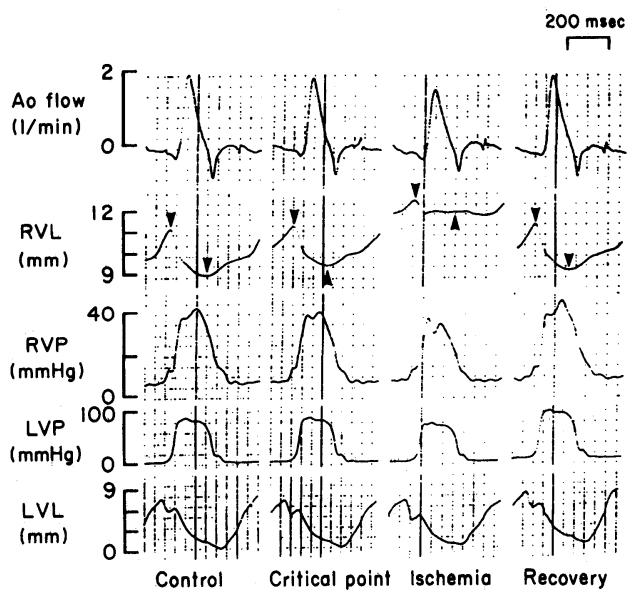

Fig. 1. Representative tracing at each stage from one dog. At the critical point, the right ventricular segment slightly increased. At ischemia, the right ventricular segment further increased and its active shortening markedly decreased. Aortic flow, right ventricular systolic pressure and left ventricular systolic pressure also decreased. At recovery, these parameters returned to the control levels. Ao flow, aortic flow; RVL, right ventricular segment length; RVP, right ventricular pressure; LVP, left ventricular pressure; LVL, left ventricular segment length. Arrow heads indicate end-diastolic or endsystolic point on right ventricular segment length.

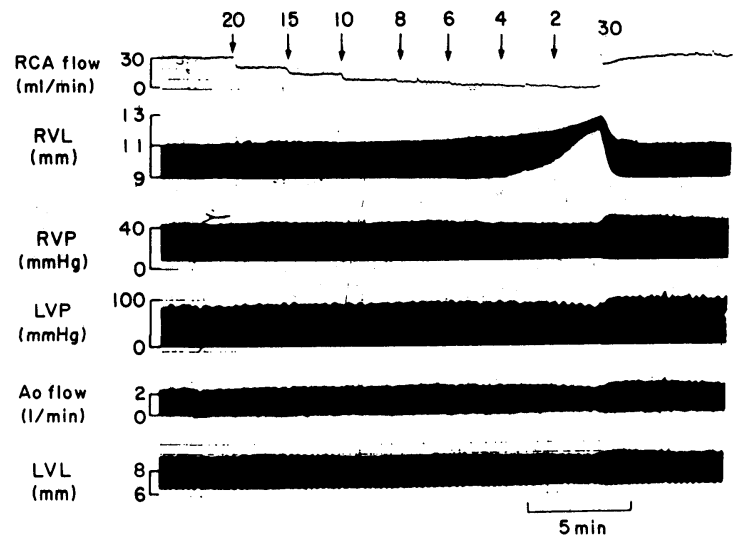

Fig. 2. Representative recording from one dog. Right coronary artery flow was reduced stepwise every three minutes. Numerals and downward arrows on the top of the figure show right coronary artery flow rate $(\mathrm{ml} / \mathrm{min})$ and the points changing to the flow rate. At critical flow, right ventricular segment began to change. Flow reduction was stopped when either right coronary flow reached zero or active shortening of the right ventricular segment disappeared, and then the flow was promptly increased to the control level (30 $\mathrm{ml} / \mathrm{min}$ ). RCA flow, right coronary flow. For other abbreveations, see Fig. 1. 
TABLE 1. Value of right ventricular systolic pressure and developed pressure at control, and right artery flow at critical point, under the conditions with and without pulmonary stenosis in each dog

\begin{tabular}{cccccccc}
\hline & \multicolumn{3}{c}{ Without PS } & & \multicolumn{3}{c}{ With PS } \\
\cline { 2 - 5 } \cline { 6 - 7 } No. & $\begin{array}{c}\text { RVSP } \\
(\mathrm{mmHg})\end{array}$ & $\begin{array}{c}\mathrm{RV} \Delta \mathrm{P} \\
(\mathrm{mmHg})\end{array}$ & $\begin{array}{c}\mathrm{CF} \\
(\mathrm{ml} / \mathrm{min})\end{array}$ & & $\begin{array}{c}\text { RVSP } \\
(\mathrm{mmHg})\end{array}$ & $\begin{array}{c}\mathrm{RV} \Delta \mathrm{P} \\
(\mathrm{mmHg})\end{array}$ & $\begin{array}{c}\mathrm{CF} \\
(\mathrm{ml} / \mathrm{min})\end{array}$ \\
\hline 1 & 29.5 & 21.3 & 1.8 & & 64.0 & 55.8 & 9.0 \\
2 & 27.7 & 20.7 & 1.53 & & 47.2 & 39.2 & 4.6 \\
3 & 27.8 & 19.3 & 1.14 & & 39.8 & 30.8 & 5.07 \\
4 & 23.0 & 15.8 & 0 & & 40.0 & 31.2 & 0.77 \\
5 & 30.5 & 21.7 & 2.53 & & 44.5 & 37.0 & 3.8 \\
6 & 23.2 & 14.7 & 3.8 & & 37.0 & 28.0 & 5.07 \\
7 & 21.3 & 16.0 & 0 & & 50.7 & 41.4 & 10.25 \\
8 & 20.8 & 13.5 & 0.97 & & 45.2 & 37.7 & 3.87 \\
9 & 24.3 & 17.3 & 1.93 & & 42.8 & 28.6 & 7.33 \\
10 & 22.6 & 17.9 & 0.73 & & 48.0 & 42.6 & 2.93 \\
Mean & 25.1 & 17.8 & 1.44 & & 45.9 & 37.2 & 5.27 \\
S.D. & 3.5 & 2.9 & 1.16 & & 7.6 & 8.4 & 2.85 \\
\hline
\end{tabular}

PS, pulmonary stenosis; RVSP, right ventricular systolic pressure; $\mathrm{RV} \Delta \mathrm{P}$, right ventricular developed pressure (RVSP - right ventricular enddiastolic pressure); CF, critical flow of right coronary artery.

TABLE 2. Segment length responses to right coronary artery flow reduction with and without pulmonary stenosis

\begin{tabular}{|c|c|c|c|c|c|c|c|c|}
\hline & \multicolumn{4}{|c|}{ Without PS } & \multicolumn{4}{|c|}{ With PS } \\
\hline & Control & $\begin{array}{l}\text { Critical } \\
\text { point }\end{array}$ & Ischemia & Recovery & Control & $\begin{array}{l}\text { Critical } \\
\text { point }\end{array}$ & Ischemia & Recovery \\
\hline $\begin{array}{l}\text { RVEDL } \\
(\mathrm{mm})\end{array}$ & $\begin{array}{r}9.83 \\
\pm 0.34\end{array}$ & $\begin{array}{r}9.99 \\
\pm 0.44\end{array}$ & $\begin{array}{r}10.33^{* *} \\
\pm 0.39\end{array}$ & $\begin{array}{r}9.80 \\
\pm 0.38\end{array}$ & $\begin{array}{r}10.32 \\
\pm 0.47\end{array}$ & $\begin{array}{r}10.40 \\
\pm 0.53\end{array}$ & $\begin{array}{r}11.21^{* *} \\
\pm 0.72\end{array}$ & $\begin{array}{r}10.41 \\
\pm 0.48\end{array}$ \\
\hline $\begin{array}{l}\text { RVESL } \\
(\mathrm{mm})\end{array}$ & $\begin{array}{r}8.17 \\
\pm 0.33\end{array}$ & $\begin{array}{r}8.45^{*} \\
\pm 0.38\end{array}$ & $\begin{array}{l}9.33^{* *} \\
\pm 0.82\end{array}$ & $\begin{array}{r}8.20 \\
\pm 0.31\end{array}$ & $\begin{array}{r}8.41 \\
\pm 0.47\end{array}$ & $\begin{array}{r}8.95^{*} \\
\pm 0.85\end{array}$ & $\begin{array}{r}11.00^{* *} \\
\pm 0.94\end{array}$ & $\begin{array}{r}8.58 \\
\pm 0.52\end{array}$ \\
\hline $\begin{array}{l}\mathrm{RV} \Delta \mathrm{L} \\
(\mathrm{mm})\end{array}$ & $\begin{array}{r}1.66 \\
\pm 0.42\end{array}$ & $\begin{array}{r}1.55 \\
\pm 0.50\end{array}$ & $\begin{array}{l}1.00^{* *} \\
\pm 0.76\end{array}$ & $\begin{array}{r}1.60 \\
\pm 0.51\end{array}$ & $\begin{array}{r}1.90 \\
\pm 0.63\end{array}$ & $\begin{array}{r}1.45^{*} \\
\pm 0.71\end{array}$ & $\begin{array}{l}0.21^{* *} \\
\pm 0.54\end{array}$ & $\begin{array}{r}1.83 \\
\pm 0.63\end{array}$ \\
\hline $\begin{array}{l}\text { LVEDL } \\
(\mathrm{mm})\end{array}$ & $\begin{array}{r}9.85 \\
\pm 0.23\end{array}$ & $\begin{array}{r}9.81 \\
\pm 0.24\end{array}$ & $\begin{array}{r}9.57^{*} \\
\pm 0.28\end{array}$ & $\begin{array}{r}9.73 \\
\pm 0.33\end{array}$ & $\begin{array}{r}9.32 \\
\pm 0.80\end{array}$ & $\begin{array}{r}9.21^{*} \\
\pm 0.82\end{array}$ & $\begin{array}{r}9.05^{*} \\
\pm 0.93\end{array}$ & $\begin{array}{r}9.28 \\
\pm 0.87\end{array}$ \\
\hline $\begin{array}{l}\text { LVESL } \\
(\mathrm{mm})\end{array}$ & $\begin{array}{r}8.02 \\
\pm 0.62\end{array}$ & $\begin{array}{r}8.00 \\
\pm 0.62\end{array}$ & $\begin{array}{r}7.89 \\
\pm 0.80\end{array}$ & $\begin{array}{r}7.90 \\
\pm 0.68\end{array}$ & $\begin{array}{r}7.70 \\
\pm 0.98\end{array}$ & $\begin{array}{r}7.69 \\
\pm 0.97\end{array}$ & $\begin{array}{r}7.66 \\
\pm 1.03\end{array}$ & $\begin{array}{r}7.64 \\
\pm 1.03\end{array}$ \\
\hline $\begin{array}{l}\mathrm{LV} \Delta \mathrm{L} \\
(\mathrm{mm})\end{array}$ & $\begin{array}{r}1.83 \\
\pm 0.64\end{array}$ & $\begin{array}{r}1.81 \\
\pm 0.64\end{array}$ & $\begin{array}{r}1.68^{*} \\
\pm 0.56\end{array}$ & $\begin{array}{r}1.83 \\
\pm 0.55\end{array}$ & $\begin{array}{r}1.62 \\
\pm 0.52\end{array}$ & $\begin{array}{r}1.53^{*} \\
\pm 0.54\end{array}$ & $\begin{array}{r}1.39^{*} \\
\pm 0.53\end{array}$ & $\begin{array}{r}1.65 \\
\pm 0.60\end{array}$ \\
\hline
\end{tabular}

All values are mean \pm s.D. of 10 dogs. RVEDL, right ventricular end-diastolic length; RVESL, right ventricular end-systolic length; RV $\Delta \mathrm{L}$, active shortening of right ventricular segment length (RVEDL-RVESL); LVEDL, left ventricular enddiastolic length; LVESL, left ventricular end-systolic length; LV $\Delta \mathrm{L}$, active shortening of left ventricular segment length (LVEDL-LVESL). $\quad{ }^{*} p<0.05 ;{ }^{* *} p<0.01$ vs. control. 
returned to the control levels.

With pulmonary stenosis, the changes in right ventricular segment lengths at ischemia became more remarkable, that is, end-diastolic length increased from $10.32 \pm 0.47$ to $11.21 \pm 0.72 \mathrm{~mm}(p<0.001)$, and end-systolic length from $8.41 \pm 0.47$ to $11.00 \pm 0.94 \mathrm{~mm}(p<0.001)$, and active shortening became almost zero (from $1.90 \pm 0.63$ to $0.21 \pm 0.45 \mathrm{~mm}, p<0.001)$. In the left ventricle, as without pulmonary stenosis, end-diastolic length at ischemia decreased from $9.32 \pm 0.80$ to $9.05 \pm$ $0.93 \mathrm{~mm}(p<0.05)$, while end-systolic length remained unchanged, and its active shortening was reduced from $1.62 \pm 0.52$ to $1.39 \pm 0.53 \mathrm{~mm}(p<0.05)$. Both ventricular segment lengths also returned to the control levels.

General hemodynamic responses to right coronary artery flow reduction are shown in Table 3. Heart rate did not change throughout the experiment in the absence of pulmonary stenosis. However, with pulmonary stenosis, heart rate slightly but significantly decreased at ischemia (from $135 \pm 13$ to $131 \pm 12$ beats/ min, $p<0.05)$. At ischemia without pulmonary stenosis, right and left ventricular systolic pressure decreased by $1.4 \pm 0.9 \mathrm{mmHg}(p<0.001)$ and $4.4 \pm$ $3.2 \mathrm{mmHg}(p<0.01)$, respectively, and left ventricular stroke volume decreased by $7.5 \pm 4.5 \%(p<0.001)$. However, left ventricular end-diastolic pressure did not change. With pulmonary stenosis, right and left ventricular systolic pressures

TABLE 3. Hemodynamic responses to right coronary artery flow reduction with and without pulmonary stenosis

\begin{tabular}{|c|c|c|c|c|c|c|c|c|}
\hline & \multicolumn{4}{|c|}{ Without PS } & \multicolumn{4}{|c|}{ With PS } \\
\hline & Control & $\begin{array}{l}\text { Critical } \\
\text { point }\end{array}$ & Ischemia & Recovery & Control & $\begin{array}{c}\text { Critical } \\
\text { point }\end{array}$ & Ischemia & Recovery \\
\hline $\begin{array}{c}\mathrm{HR} \\
\text { (beasts/min) }\end{array}$ & $\begin{array}{r}137 \\
\pm 15\end{array}$ & $\begin{array}{r}137 \\
\pm 14\end{array}$ & $\begin{array}{r}136 \\
\pm 14\end{array}$ & $\begin{array}{r}136 \\
\pm 15\end{array}$ & $\begin{array}{r}135 \\
\pm 13\end{array}$ & $\begin{array}{r}135 \\
\pm 12\end{array}$ & $\begin{array}{l}131^{*} \\
\pm 12\end{array}$ & $\begin{array}{r}132 \\
\pm 14\end{array}$ \\
\hline $\begin{array}{c}\text { RVSP } \\
(\mathrm{mmHg})\end{array}$ & $\begin{array}{r}25.1 \\
\pm 3.5\end{array}$ & $\begin{array}{l}25.5^{*} \\
\pm 3.0\end{array}$ & $\begin{array}{r}23.7^{* *} \\
\pm 3.0\end{array}$ & $\begin{array}{r}25.3 \\
\pm 3.3\end{array}$ & $\begin{array}{r}45.9 \\
\pm 7.6\end{array}$ & $\begin{array}{l}44.7^{*} \\
\pm 6.5\end{array}$ & $\begin{array}{r}37.8^{* *} \\
\pm 8.5\end{array}$ & $\begin{array}{r}44.9 \\
\pm 6.9\end{array}$ \\
\hline $\begin{array}{l}\text { RVEDP } \\
\text { (mmHg) }\end{array}$ & $\begin{array}{r}7.3 \\
+1.4\end{array}$ & $\begin{array}{r}7.2 \\
\pm 1.4\end{array}$ & $\begin{array}{r}7.3 \\
\pm 1.3\end{array}$ & $\begin{array}{r}6.9 \\
\pm 1.6\end{array}$ & $\begin{array}{r}8.7 \\
\pm 2.2\end{array}$ & $\begin{array}{r}8.5 \\
\pm 2.5\end{array}$ & $\begin{array}{r}9.1 \\
\pm 2.5\end{array}$ & $\begin{array}{r}8.7 \\
\pm 2.5\end{array}$ \\
\hline $\begin{array}{c}\text { LVSP } \\
(\mathrm{mmHg})\end{array}$ & $\begin{array}{r}111 \\
\pm 18\end{array}$ & $\begin{array}{l}108^{*} \\
\pm 19\end{array}$ & $\begin{array}{r}107^{* *} \\
\pm 19\end{array}$ & $\begin{array}{r}107 \\
\pm 22\end{array}$ & $\begin{array}{r}101 \\
\pm 24\end{array}$ & $\begin{array}{l}100^{*} \\
\pm 23\end{array}$ & $\begin{array}{l}92^{* *} \\
\pm 25\end{array}$ & $\begin{array}{r}99 \\
+25\end{array}$ \\
\hline $\begin{array}{l}\text { LVEDP } \\
(\mathrm{mmHg})\end{array}$ & $\begin{array}{r}8.6 \\
+2.5\end{array}$ & $\begin{array}{r}8.7 \\
\pm 2.8\end{array}$ & $\begin{array}{r}8.5 \\
+2.8\end{array}$ & $\begin{array}{r}8.3 \\
\pm 2.2\end{array}$ & $\begin{array}{r}8.4 \\
+2.2\end{array}$ & $\begin{array}{r}8.4 \\
\pm 2.6\end{array}$ & $\begin{array}{r}8.5 \\
\pm 2.3\end{array}$ & $\begin{array}{r}8.4 \\
\pm 2.3\end{array}$ \\
\hline $\begin{array}{l}\mathrm{SV} \\
(\mathrm{ml})\end{array}$ & $\begin{array}{r}10.7 \\
\pm 4.6\end{array}$ & $\begin{array}{r}10.2^{* *} \\
\pm 4.3\end{array}$ & $\begin{array}{l}9.8^{* *} \\
\pm 3.9\end{array}$ & $\begin{array}{r}10.7 \\
\pm 3.7\end{array}$ & $\begin{array}{r}8.3 \\
\pm 2.3\end{array}$ & $\begin{array}{r}8.2 \\
\pm 2.1\end{array}$ & $\begin{array}{l}7.0^{* *} \\
\pm 2.2\end{array}$ & $\begin{array}{r}8.6 \\
\pm 2.5\end{array}$ \\
\hline $\begin{array}{c}\% \mathrm{SV} \\
(\%)\end{array}$ & 100 & $\begin{array}{r}95.0^{* *} \\
\pm 4.4\end{array}$ & $\begin{array}{r}92.5^{* *} \\
\pm 4.5\end{array}$ & $\begin{array}{l}101.4 \\
\pm 8.1\end{array}$ & 100 & $\begin{array}{r}99.0 \\
\pm 4.5\end{array}$ & $\begin{array}{l}84.9^{* *} \\
\pm 10.2\end{array}$ & $\begin{array}{l}103.7 \\
\pm 6.0\end{array}$ \\
\hline
\end{tabular}

All values are mean \pm S.D. of 10 dogs. HR, heart rate; RVSP, right ventricular systolic pressure; RVEDP, right ventricular end-diastolic pressure; LVSP, left ventricular systolic pressure; LVEDP, left ventricular end-diastolic pressure; SV, stroke volume; $\% \mathrm{SV}$, percent stroke volume of each control value. ${ }^{*} p<0.05 ;{ }^{* *} p<$ 0.01 vs. control. 

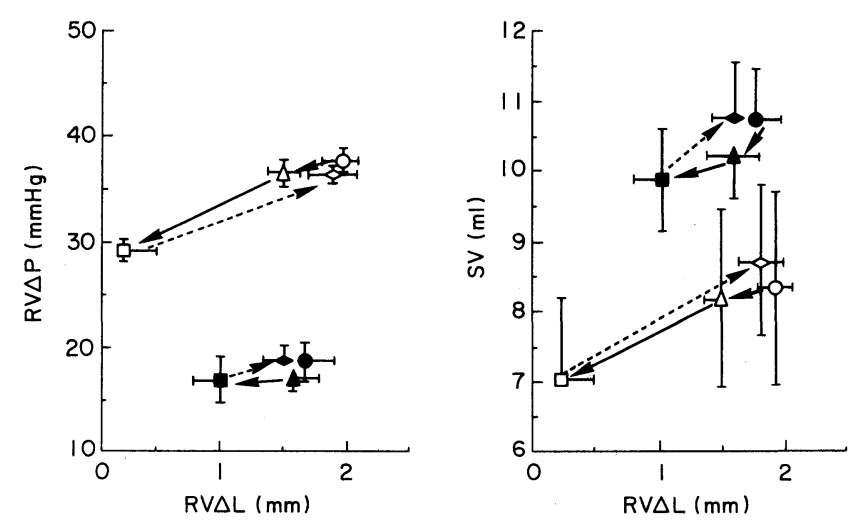

Fig. 3. Relationships between active shortening of the right ventricular segment $(\mathrm{RV} \Delta \mathrm{L})$ and right ventricular developed pressure (RV $\Delta \mathrm{P}$; left panel) and stroke volume (SV; right panel) with (open symbols) and without pulmonary artery constriction (closed symbols). In this figure data are mean \pm s.e. Solid lines join control $(\bullet, \bigcirc)$ and the critical point $(\Delta, \Delta)$ or the critical point and ischemia $(\square, \square)$. Dotted lines join ischemia and recovery $(\diamond, \diamond)$. See text for details.

and left ventricular stroke volume also decreased by $8.2 \pm 5.0 \mathrm{mmHg}(p<0.001)$, $9.2 \pm 4.6(p<0.001)$, and $15.1 \pm 10.2 \%(p<0.01)$, respectively, while both enddiastolic pressures remained unchanged. However the decreases in right and left ventricular systolic pressures were larger than those without pulmonary stenosis $(p<0.01$ for right ventricular systolic pressure, $p<0.01$ for left ventricular systolic pressure). These changes returned to control levels at recovery in both conditions, with and without pulmonary stenosis.

Fig. 3 shows the relationships between active shortening of the right
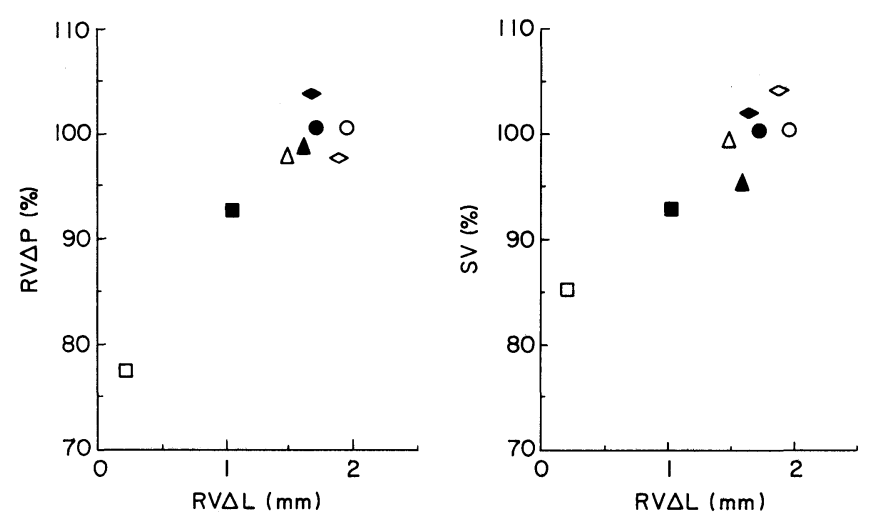

Fig. 4. The relationships between active shortening of the right ventricular segment $(\mathrm{RV} \Delta \mathrm{L})$ and percent change in right ventricular developed pressure (RV $\triangle \mathrm{P}$; left panel) and stroke volume (SV; right panel). Symbols; see Fig. 3. See text for details. 
ventricular segment $(\mathrm{RV} \Delta \mathrm{L})$ and right ventricular developed pressure $(\mathrm{RV} \Delta \mathrm{P}$, left panel) and left ventricular stroke volume (SV, right panel). Without pulmonary stenosis (closed symbols), $\mathrm{RV} \Delta \mathrm{L}$ on the abscissa and right ventricular developed pressure or left ventricular stroke volume on the ordinate at ischemia, and each corresponding data point shifted downward to the left, as shown by solid lines. When right coronary artery flow was restored, $\mathrm{RV} \Delta \mathrm{L}$, right ventricular developed pressure and stroke volume recovered and the data points returned to control values through the dotted lines. With pulmonary stenosis, as right ventricular developed pressure became larger and stroke volume smaller, the data point (open symbols) was located in the upper part of the left panel and in the lower part of the right panel. In addition, because the decreases in $\mathrm{RV} \Delta \mathrm{L}$, right ventricular developed pressure and stroke volume at ischemia were more prominent than without pulmonary stenosis, the data points (open squares) in each panel more clearly shifted downward to the left, compared with those without pulmonary stenosis (closed square).

Fig. 4 shows relationships between the same parameters in Fig. 3, except that $\mathrm{RV} \triangle \mathrm{L}$ and $\mathrm{SV}$ is shown as a percent of each control value. Right ventricular developed pressure and left ventricular stroke volume decreased in accordance with the reduction in $\mathrm{RV} \Delta \mathrm{L}$, and the degree of the decreases in those parameters at $\mathrm{RV} \triangle \mathrm{L}$ of zero were estimated to be about $20 \%$, respectively.

\section{Discussion}

In the present study, we induced a depression of right ventricular free wall function by means of reduction in right coronary artery flow. In dog, since the right coronary artery distributes to the right ventricular free wall, not to the left ventricle or the interventricular septum (Goldstein et al. 1982; Goto et al. 1985), the reduction in coronary artery flow causes a depressed state of the right ventricular free wall movement without disturbance of the left ventricle. Therefore, the right coronary artery flow reduction employed in the present experiment is useful for evaluating the significance of the right ventricular free wall in cardiac function.

In the present study, ultrasonic miniature dimension gauges were implanted in the right and left ventricular free wall through the small incisions in the pericardium as previously reported (Shirato et al. 1978, 1982; Kanazawa et al. 1983). In addition, an electromagnetic flow probe was set around the ascending aorta through an another incision in the pericardium like as in a previous report (Kanazawa et al. 1983). These incisions were loosely sutured with care not to diminish the original pericardial space. If this procedure caused a reduction in the pericardial space, the effects of pericardium on the present results would be enhanced. However, this technique was evaluated by Stokland et al. (1980) and Kanazawa et al. (1983), who found that it kept the pericardium intact. In the present study, an additional small incision was made in the pericardium for 
dissecting the right coronary artery near its origin. This incision was also loosely sutured. Therefore, the method used in the present study for the implantation of crystals, the setting of flow probe and the dissection of coronary artery should not induce erronous results.

The present study clearly demonstrated that, when right coronary artery flow was reduced to a level below the critical point, an active shortening of the right ventricular free wall decreased with lengthening of its end-diastolic and endsystolic segment lengths, and that the right ventricular systolic pressure and left ventricular stroke volume simultaneously decreased. These changes were observed even in normal pulmonary circulation and became more prominent when the right ventricle was stressed by pressure overload. Thus, it is concluded that the right ventricular free wall partly contributes to maintaining right ventricular function, especially during right ventricular pressure overload.

Starr et al. (1943) showed that the central venous pressure did not increase after the right ventricular free wall was severely damaged by thermal injury in animal experiments. Similar results were also reported by other investigators (Bakos 1950; Kagan 1952). Thus, the right ventricular free wall has been thought not to participate in maintaining right ventricular function. Brooks et al. (1971) also reported that right coronary artery occlusion caused no change in cardiac output and both right and left ventricular systolic pressures under normal pulmonary circulation in open chest dog. However, they showed that when the pulmonary artery was obstructed by a balloon catheter, right coronary occlusion significantly decreased these parameters. Therefore, they concluded that right coronary artery flow might be an important factor leading to right ventricular failure under the stressed condition of pressure overload. However, they could find no significant role for the right ventricular free wall in normal pulmonary circulation, as in previous investigations (Starr et al. 1943; Bakos 1950; Kagan 1952). They simultaneously recorded the contractile force of the right ventricular free wall using an isometric strain gauge arch and showed the contractile force to be markedly reduced by right coronary occlusion in conditions both with and without the pressure overload. In the present experiment, the right ventricular systolic pressure and left ventricular stroke volume decreased in accordance with the decrease in active shortening of the right ventricular free wall in both conditions, i.e., with and without pulmonary stenosis.

We can not clearly explain why our results differ from those of Brooks et al. (1971) in normal pulmonary circulation, but the following mechanism for this difference might be considered. We performed the experiment in dog with the pericardium preserved, while that of Brooks et al. (1971) was with the pericardium removed. Since the pericardium prevents the heart from over-distending (Shirato et al. 1978; Kanazawa et al. 1983), there is a possibility that the pericardium prevented the right ventricular free wall from over-stretching at ischemia and lessened the increase in right ventricular end-diastolic volume, compared to the 
volume with the pericardium removed. Thus, the present study appears to show that the right ventricular systolic pressure and left ventricular stroke volume decreased slightly but significantly even in normal pulmonary circulation, because the presence of the pericardium would lessen the effects of Frank-Starling mechanism.

When the right ventricular systolic pressure was increased by means of pulmonary stenosis, the level of critical flow of the right coronary artery increased and the decreases in right ventricular developed pressure and active shortening at ischemia became more prominent. In addition, the degree of the decrease in left ventricular stroke volume with right ventricular pressure overload showed a tendency to be larger than that without pressure overload. Thus, the results indicate that right coronary artery flow is an important factor in maintaining the right ventricular function and that demand for the right coronary flow increases when the right ventricle is stressed by right ventricular pressure overload. Since an increase in demand for coronary flow reflects an increase in myocardial oxygen consumption, it is suggested that the increase in afterload for the right ventricle by pulmonary stenosis augmented oxygen consumption of the ventricular free wall through an increase in right ventricular wall stress caused by increases in preload and afterload for the wall. Kusachi et al. (1982) showed that constriction of the pulmonary artery increases myocardial oxygen consumption of the right ventricle by both augmented oxygen extraction and a rise in right coronary blood flow. Thus, more prominent deterioration of right ventricular wall movement at ischemia in right ventricular pressure overload, compared to the condition with normal pulmonary circulation, appeared to be mainly due to the increase in ischemic change of the right ventricular wall muscle, although the increase in afterload for the right ventricular wall could mechanically depress the right ventricular wall motion.

In the present experiment, we estimated the contributions of the right ventricular free wall to right ventricular pressure development and pump function to be about $20 \%$, respectively. Goldstein et al. (1982) showed that, after isolated right ventricular infarction in dogs with the pericardium preserved, right ventricular systolic pressure decreased by $27 \%$ and cardiac output by $34 \%$, respectively. These changes seemed to be larger than those in our experiment. The differing results appear to depend on the degree of deterioration of right ventricular wall motion caused by ischemia. We estimated the contribution of the right ventricular wall at $\mathrm{RV} \Delta \mathrm{L}$ of zero. However, the results of Goldstein et al. (1982) appear to have been obtained under the conditions in which the right ventricular wall motion was further deteriorated, that is, showing pansystolic expansion, which might further lessen the ventricular pressure development and stroke volume, compared to the condition at $\mathrm{RV} \Delta \mathrm{L}$ of zero. Thus, the net right ventricular wall contribution to the ventricular function could be estimated to be about $20 \%$, although the ventricular function in right ventricular infarction was 
further deteriorated due to the pansystolic expansion of the right ventricular free wall.

In the left ventricle at right ventricular ischemia, systolic pressure significantly decreased with fall in stroke volume, and end-diastolic length and active shortening clearly decreased with no change in end-systolic length and no change in the ventricular end-diastolic pressure under conditions with and without right ventricular pressure overload. These results suggest that the fall in left ventricular systolic pressure and stroke volume were due to the decrease in preload of the left ventricle. Mechanisms for the decrease in preload of the left ventricle might be as follows: as the right ventricular stroke volume decreased at ischemia, venous return to the left ventricle was consequently reduced because the right and left ventricles are placed in series via pulmonary circulation. Another possible mechanism might be an enhancement of diastolic interaction between the ventricles. Because of an anatomical association established by the interventricular septum and common muscle bundle surrounding both ventricles, an increase in one ventricular volume would modify the opposite ventricular diastolic properties (Taylor et al. 1967; Bemis et al. 1974; Elzinga et al. 1974). In addition, it has been postulated that this diastolic interaction between the two ventricles would be enhanced by the pericardium (Janicki and Weber 1978; Spadaro et al. 1979, 1981; Shirato et al. 1982). It was also reported that when the right ventricle is loaded, the interventricular septum shifts toward the left ventricle (Bemis et al. 1974; Santamore et al. 1976; Glantz et al. 1978; Goto et al. 1985). Thus, in the present experiment, the increase in right ventricular volume at ischemia might also modify the left ventricular diastolic pressure-volume relationship, that is, decrease in end-diastolic length with no change in enddiastolic pressure, and disturb blood filling to the left ventricle. It has also been pointed out that left ventricular contraction affects right ventricular systolic function through a mechanical interaction between the two ventricles (Elzinga et al. 1980). Thus, the decrease in left ventricular systolic pressure appeared to enhance the decreases in right ventricular developed pressure and stroke volume at ischemia.

We investigated the significance of the right ventricular free wall in the ventricular function. When the right ventricular wall motion was depressed by means of right coronary artery flow reduction, right ventricular developed pressure decreased, and consequently left ventricular systolic pressure and stroke volume decreased. These changes were more prominent in the presence of right ventricular pressure loading than in normal pulmonary circulation. Thus, it is concluded that the right ventricular free wall partly contributes to maintaining the right ventricular function, especially during right ventricular pressure overload. The present experiment was performed in open chest dogs with positive pressure ventilation and right ventricular pressure overload was produced by means of pulmonary stenosis. Therefore, the condition is dissimilar to the 
pulmonary hypertension in clinical settings, but these results may be applied for patients with right ventricular pressure overload, e.g. pulmonary thromboembolism and acute bronchospasm, or with right coronary artery stenosis.

\section{References}

1) Bakos, A.C.P. (1950) The question of the function of the right ventricular myocardium: An experimental study. Circulation, 1, 724-732.

2) Bemis, C.E., Serur, J.R., Borkenhagen, D., Sonnenblick, E.H. \& Urschel, C.W. (1974) Influence of right ventricular filling pressure on left ventricular pressure and dimension. Circ. Res., 34, 498-504.

3) Brooks, H., Kirk, E.S., Vokonas, P.S., Urschel, C.W. \& Sonnenblick, E.M. (1971) Performance of the right ventricle under stress: Relation to right coronary flow. $J$. Clin. Invest., 50, 2176-2183.

4) Cohn, J.N., Guiha, N.H., Broder, M.I. \& Limas, C.J. (1974) Right ventricular infarction: Clinical and hemodynamic features. Am. J. Cardiol., 33, 209-214.

5) Coma-Canella, I. \& Lopez-Sendon, J. (1980) Ventricular compliance in ischemic right ventricular dysfunction. Am. J. Cardiol., 45, 555-561.

6) Coma-Canella, I., Lopez-Sendon, J. \& Gamallo, C. (1979) Low output syndrome in right ventricular infarction. Am. Heart J., 98, 613-620.

7) Elzinga, G., Grondelle, R.V., Westerhof, N. \& Bos, G.C.V.D. (1974) Ventricular interference. Am. J. Physiol., 226, 941-947.

8) Elzinga, G., Pierne, H. \& DeJong, J.P. (1980) Left and right ventricular pump function and consequences of having two pumps in one heart. Circ. Res., 46, 564-574.

9) Glantz, S.A., Misbach, G.A., Moores, W.Y., Mathey, D.G., Lekven, J., Strowe, D.F., Parmley, W.W. \& Tyberg, J.W. (1978) The pericardium substantially affects the left ventricular diastolic pressure-volume relationship in the dog. Circ. Res., 42, 433-441.

10) Goldstein, J.A., Vlahakes, G.J., Verrier, E.D., Schiller, N.B., Tyberg, J.V., Ports, T.A., Parmley, W.W. \& Chatterjee, K. (1982) The role of right ventricular systolic dysfunction and elevated intrapericardial pressure in the genesis of low output in experimental right ventricular infarction. Circulation, 65, 513-522.

11) Goto, Y., Yamamoto, J., Saito, M., Haze, K., Sumiyoshi, T., Fukami, K. \& Hiramori, K. (1985) Effects of right ventricular ischemia on left ventricular geometry and the end-diastolic pressure-volume relationship in the dog. Circulation, 72, 1104-1114.

12) Janicki, J.S. \& Weber, K.T. (1978) Ventricular interaction pre-and post pericardiectomy. Fed. Proc., 37, 776. (Abstract)

13) Kagan, A. (1952) Dynamic responses of the right ventricle following extensive damage by cauterization. Circulation, 5, 816-823.

14) Kanazawa, M., Shirato, K., Ishikawa, K., Nakajima, T., Haneda, T. \& Takishima, T. (1983) The effect of pericardium on the end-systolic pressure-segment length relationship in canine left ventricle in acute volume overload. Circulation, 68, 1290-1298.

15) Kusachi, S., Nishiyama, O., Yasuhara, K., Saito, D., Haraoka, S. \& Nagashima, H. (1982) Right and left ventricular oxygen metabolism in open-chest dogs. Am. J. Physiol., 243, H761-H766.

16) Lloyd, E.A., Gersh, B.J. \& Kennelly, B.M. (1981) Hemodynamic spectrum of "dominant" right ventricular infarction in 19 patients. Am. J. Cardiol., 48, 10161022.

17) Lopez-Sendon, J., Coma-Canella, I. \& Gamallo, C. (1981) Sensitivity and specificity of hemodynamic criteria in the diagnosis of acute right ventricular infarction. Circulation, 64, 515-525.

18) Lorell, B., Leinbach, R.C., Pohost, G.M., Gold, H.K., Dismore, R.E., Hutter, A.M., Jr., Pastore, J.O. \& Desanctis, R.W. (1979) Right ventricular infarction; clinical diagno- 
sis and differentiation from cardiac tamponade and pericardiac constriction. Am. J. Cardiol., 43, 465-471.

19) Pouleur, H., Lefevre, J., Mechelen, H.V. \& Charlier, A.A. (1980) Free-wall shortening and relaxation during ejection in the canine right ventricle. Am. J. Physiol., 239, H601-H631.

20) Rushmer, R.F., Crystal, D.K. \& Wagner, C. (1953) The functional anatomy of ventricular contraction. Circ. Res., 1, 162-170.

21) Santamore, W.P., Lynch, P.R., Meier, G., Heckman, J. \& Bove, A.A. (1976) Myocardial interaction between the ventricles. J. Appl. Physiol., 41, 362-368.

22) Shirato, K., Shabetai, R., Bhargava, V., Franklin, D. \& Ross, J., Jr. (1978) Alteration of the left ventricular diastolic pressure-segment length relation produced by the pericardium. Circulation, 57, 1191-1198.

23) Shirato, K., Kanazawa, M., Ishikawa, K., Nakajima, T. \& Takishima, T. (1982) The effect of pericardium on the diastolic properties of the heart; Experimental studies on volume load and on acute ischemia in open chest dogs. Jpn. Circ. J., 46, 113-123.

24) Spadaro, J., Bing, O.H.L., Gaasch, W.H., Franklin, A.F. \& Weintraub, R.M. (1979) Pericardial modulation of right and left ventricular diastolic interaction. Circulation, 60, II-93. (Abstract)

25) Spadaro, J., Bing, O.H.L., Gaasch, W.H. \& Weintraub, R.M. (1981) Pericardial modulation of right and left ventricular diastolic interaction. Circ. Res., 48, 233-238.

26) Starr, I., Jeffers, W.A. \& Meade, R., Jr. (1943) The absence of conspicuous increments of venous pressure after severe damage to the right ventricle of the dog, with a discussion of the relation between clinical congestive failure and heart disease. $\mathrm{Am}$. Heart J., 26, 291-301.

27) Stokland, O., Miller, M.M., Lekven, J. \& Ilebekk, A. (1980) The significance of the pericardium for cardiac performance in the dog. Circ. Res., 47, 27-32.

28) Taylor, R.R., Covell, J.W., Sonnenblick, E.H. \& Ross, J., Jr. (1967) Dependence of ventricular distensibility on filling of the opposite ventricle. Am. J. Physiol., 213, 711-718. 